\title{
ВОПРОСЫ ИНСТРУМЕНТАЛЬНОГО ОБЕСПЕЧЕНИЯ НАРЕЗАНИЯ ДВУХПАРАМЕТРИЧЕСКИХ ЗУБЧАТЫХ КОЛЕС
}

\section{BUSINESS SOFTWARE TOOL CUTTING TWO-PARAMETER GEARS}

\author{
Представил д-р техн. наук, профессор Н.В. Верезуб
}

\begin{abstract}
Постановка проблематики в общем виде, ее связь с важными научными и практическими заданиями. Современное машиностроение, в том числе ее отрасли "Машины для производства строительных материалов и конструкций”, “Машины для дорожных работ", "Подъемнотранспортные машины” и т. д., требует, с одной стороны, создания машин и механизмов с расширенными функциональными возможностями, а с другой - предъявляет к ним все более жесткие требования по весогабаритным характеристикам.

Срединное положение передачи в структуре практически любой машины определяет ее центральную роль и, следовательно, тесную взаимосвязь, с одной стороны, с двигателем, а с другой - с исполнительным механизмом, что в конечном итоге формирует выходные показатели всей машины в целом. Развитие зубчатых зацеплений в настоящее время характеризуется двумя направлениями: совершенствованием традиционных и созданием новых типов и видов передач.

Существующие традиционные зубчатые передачи не всегда позволяют синтезировать простые и надежные регулируемые приводы, так как по своей геометрической природе являются однопараметрическими и не имеют
\end{abstract}

возможности осуществлять регулирование по нескольким параметрам.

Поэтому возникла проблема создания регулируемых зубчатых зацеплений, которые могли бы не только осуществлять непрерывную передачу крутящего момента, но и одновременно изменять другие параметры, например, межцентровое расстояние, углы скрещивания, передаточные отношения, и иметь сравнимые с традиционными приводами габариты и массу, оставаясь технологичными и надежными в эксплуатации.

Значительный прогресс в области разработки и создания таких регулируемых зубчатых передач был достигнут благодаря работам В.Р. Ковалюха, в которых он доказал возможность регулирования параметров в высшей кинематической паре благодаря использованию нового класса двухпараметрических зацеплений [1-3].

Анализ последних исследований и публикаций. В последние годы в Украине появились новые теоретические и практические возможности для изучения формообразования специальных зубчатых колес. Благодаря применению и развитию многопараметрических отображений пространства созданы алгоритмы совместного геометрического проектирования зубчатых колес, зубообрабатывающих инструментов и 
формообразования в неразрывной взаимосвязи в единой инструментальной системе. Многозвенные инструментальные системы описаны обобщенной структурой отображений и систематизацией отдельных структур, которая охватывает однопараметрические и двухпараметрические рабочие и станочные зубчатые зацепления с разными сочетаниями сопряженных профилей, начальных поверхностей, кинематики, взаимного расположения колёс [4, 5]. В Украине на базе НТУ "Харьковский политехнический институт" и $3 \mathrm{AO}$ "Конструкторско-технологическое бюро верификационного моделирования и подготовки производства" в 2001 году создан учебно-научно-производственный центр интегрированных технологий ускоренного изготовления прототипов, инструментального обеспечения и производства изделий Rapid Prototyping, Rapid Tooling, Rapid Manufacturing (RPTM) [6].

Цель исследования: усовершенствовать процессы формообразования зубчатых колёс с постоянным нормальным шагом для специальных двухпараметрических зацеплений.

Основная часть. В результате проведенных исследований предлагается ряд новых методов формообразования и обкаточных инструментов для предварительной обработки - обкаточные лезвийные инструменты (резцы для зуботочения) [7], и для окончательной обработки - среди них это шеверы, зубчатые хоны и режуще-деформирующие обкатники с точечным контактом.

Опишем обкаточные инструменты для обработки, например, сферических зубчатых колес с постоянным нормальным шагом, полученные на основе цилиндрического производящего колеса с точечным контактом. Это колесо скрещивается с обрабатываемым сферическим колесом и, обкатываясь по нему, перемещается вдоль его зубьев. Такая кинематика характерна для процесса шевингования. Применимость этого процесса к сферическим зубчатым колесам можно доказать наличием продольного (бреющего) скольжения зубьев. Известно, что скорость продольного скольжения зубьев $\bar{V}_{c \kappa}$ направлена по касательной к линии зуба на начальной поверхности [8].

Скорость вращения обрабатываемого сферического колеса вокруг своей оси $\bar{V}_{1}$ в точке $P_{0}$ касания начальных поверхностей раскладывается на скорость $\bar{V}_{1}^{\prime}$ и скорость скольжения $\bar{V}_{c \kappa l}$ (рис. 1).

Скорость $\bar{V}_{1}^{\prime}$ по величине и направлению равна скорости $\bar{V}_{2}$ вращения точки $P_{0}$ вместе с цилиндрическим производящим колесом (будущим шевером) вокруг его оси с параметром $\varphi_{2}$. Дифференцируя уравнения движения по параметрам $\varphi_{1}$ и $\varphi_{2}$, получаем проекции $\bar{V}_{1}$ и $\bar{V}_{2}$ на оси координат:

$$
\begin{aligned}
& V_{l_{x_{1}}}=-x_{0_{1}} \sin \varphi_{1}-y_{0_{1}} \cos \varphi_{1} ; \\
& V_{l_{y_{1}}}=x_{0_{1}} \cos \varphi_{1}-y_{0_{1}} \sin \varphi_{1} ; \\
& V_{l_{z_{1}}}=0 ; \\
& V_{2_{x_{1}}}=-x_{0_{2}} \sin \varphi_{2}-y_{0_{2}} \cos \varphi_{2} ; \\
& V_{2_{y_{1}}}=x_{0_{2}} \cos \varphi_{2}-y_{0_{2}} \sin \varphi_{2} ; \\
& V_{2_{z_{1}}}=0,
\end{aligned}
$$

где $x_{0_{1}}, y_{0_{1}}, z_{0_{1}}-$ координаты точки $P_{0}$ в системе координат сферического колеса;

$x_{O_{2}}, y_{O_{2}}, z_{0_{2}}-$ координаты точки $P_{0}$ в системе координат цилиндрического колеса. 

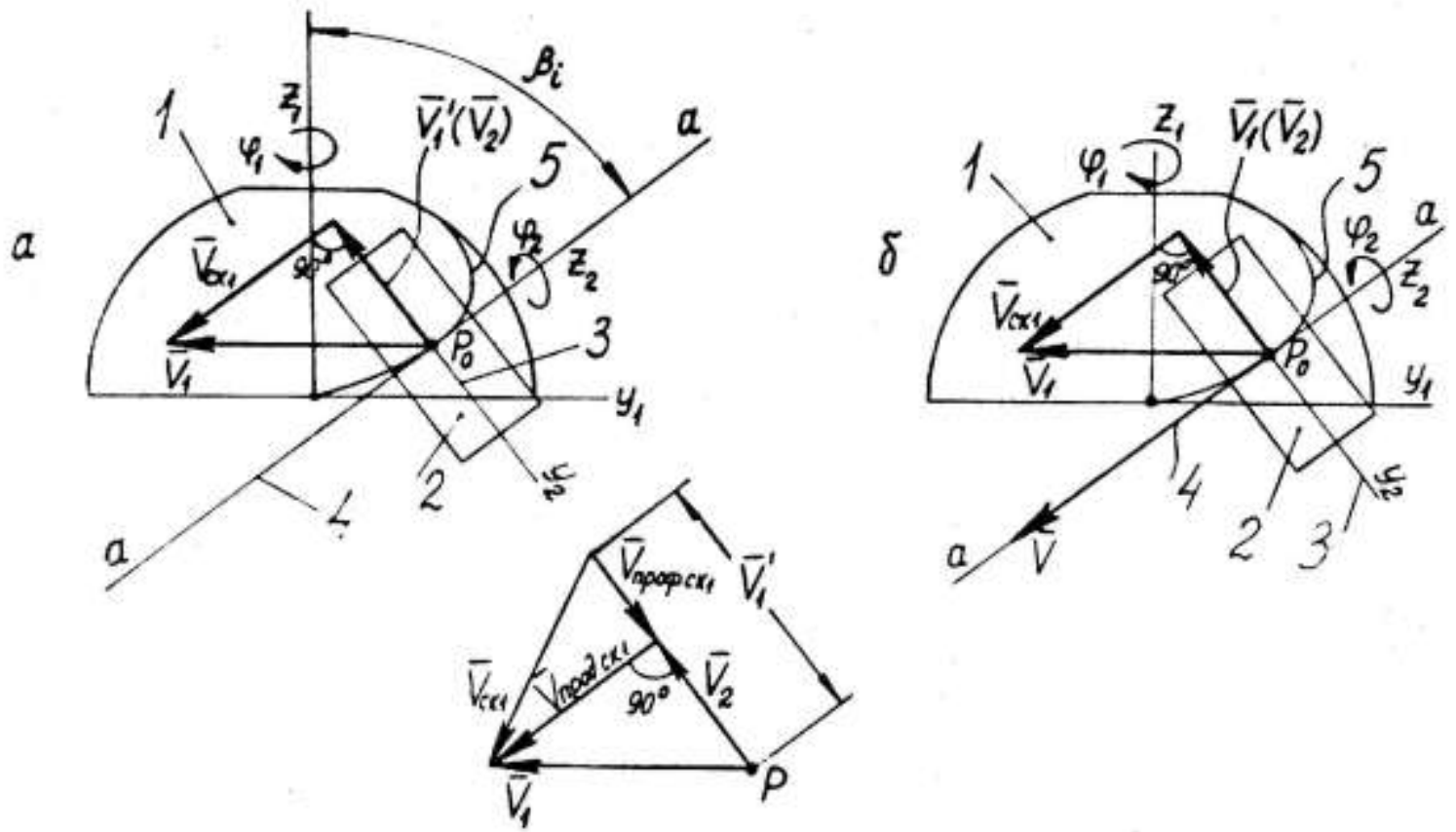

Рис. 1. Доказательство наличия скольжения поверхностей зубьев шевера и обрабатываемого сферического колеса:

1 - начальная сфера обрабатываемого колеса; 2 - начальный цилиндр шевера; 3 - нормаль к линии зуба обрабатываемого колеса; 4 - касательная к линии зуба; 5 - линия зуба

Переведя $\bar{V}_{2}$ из системы координат $x_{2} y_{2} z_{2}$ в систему $x_{1} y_{1} z_{1}$, то есть получив $\bar{V}_{1}$, можем найти вектор скорости продольного скольжения поверхности зуба сфери- ческого колеса по зубу цилиндрического $\bar{V}_{c \kappa l \text { как разность }} \bar{V}_{1}-\bar{V}_{1}^{\prime}$ :

$$
\begin{aligned}
& V_{c k_{x_{1}}}=-x_{0_{1}} \sin \varphi_{1}-y_{0_{1}} \cos \varphi_{1}+i\left(x_{0_{2}} \sin \varphi_{2}+y_{0_{2}} \cos \varphi_{2}\right) ; \\
& V_{c c_{l_{y_{1}}}}=x_{0_{1}} \cos \varphi_{1}-y_{0_{1}} \sin \varphi_{1}-i \cos \beta\left(x_{0_{2}} \cos \varphi_{2}-y_{0_{2}} \sin \varphi_{2}\right) ; \\
& V_{c l_{z_{1}}}=-i \sin \beta\left(x_{0_{2}} \cos \varphi_{2}-y_{0_{2}} \sin \varphi_{2}\right) .
\end{aligned}
$$

Заметим, что формулы (3) относятся к линии зуба на начальной сфере и, следовательно, характеризуют именно скорость продольного скольжения при отсутствии составляющей профильного скольжения. На других эквидистантных линиях зуба, расположенных выше или ниже начальной сферы, в момент контакта сопрягаемых поверхностей имеются две составляющих скорости скольжения $\bar{V}_{c \kappa l}$ :

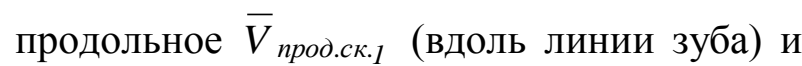
профильное $\bar{V}_{\text {проф.ск. }}$ (по нормали к линии зуба). Ранее было доказано, что вращение с параметрами $\psi_{1}, \psi_{2}, \beta_{\text {до }}$ в их взаимосвязи сводятся к мгновенному перемещению (скольжению) звеньев вдоль касательной к линии зуба $\bar{K}$ со скоростью $\bar{V}$. Тогда исходя из этого факта можно констатировать, что к суммарному 
мгновенному винтовому движению звеньев относительно касательной $\bar{K}$ добавляется еще одно скольжение $\bar{V}$. Таким образом, доказано наличие скоростей взаимного скольжения сопрягаемых поверхностей, следовательно, шевингование сферических зубчатых колес с постоянным нормальным
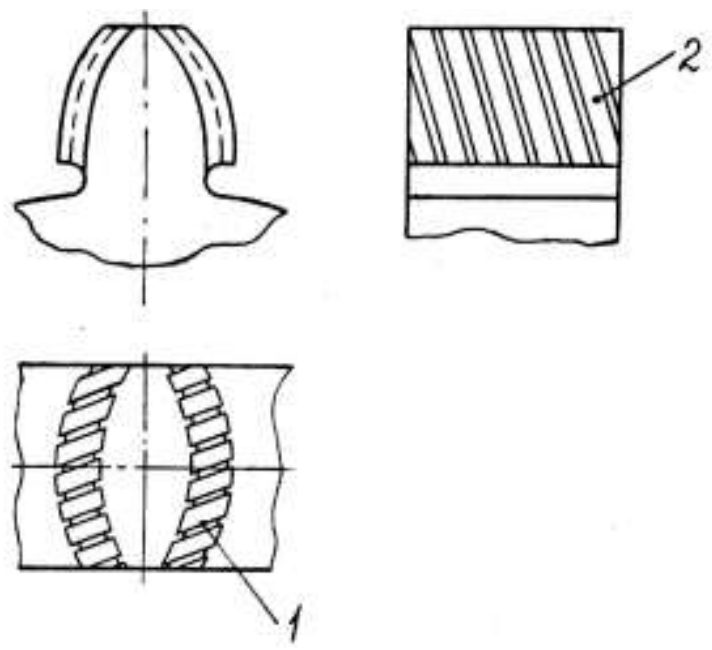

шагом возможно. Режущие кромки шевера 1 получаются как линии пересечения производящей поверхности 2 с передней поверхностью стружечных канавок (рис. 2). Угол наклона стружечных канавок нужно выбирать исходя из направления суммарной скорости скольжения.

Рис. 2. Зуб шевера для обработки сферического колеса

Очевидно, что наличие скольжения зубьев позволяет рекомендовать также абразивное и алмазное хонингование зубьев сферических колес [9]. На рис. 3 показан, например, чертеж алмазного эластичного зубчатого хона с модулем 7 мм и числом зубьев 31 для отделочной обработки зубьев закаленных зубчатых колес.

Конструкция основана на предложениях и рекомендациях Института сверхтвердых материалов (ИСМ, Киев). Зубчатый венец имеет эластичный слой 1 из упругого материала. На боковых поверхностях бочкообразных зубьев имеется алмазоносный слой 2 толщиной от 0,8 до 1,5 мм. Зернистость, концентрация алмазов и связка назначаются в зависимости от обрабатываемого материала. В ИСМ освоена прогрессивная технология изготовления таких хонов для цилиндрических колес. По данным этого института они обеспечивают шероховатость в диапазоне $R_{a}=0,8-0,2$ мкм. По сравнению с абразивными зубчатыми хонами на эпоксидных связках алмазные эластичные хоны могут обработать в 10 раз больше колес при равном объеме изношенного слоя (до 2-6 тыс. колес средних модулей).

Цилиндрическое производящее колесо с точечным контактом также может быть превращено в деформирующий обкатник. Причем его зубья будут состоять из трех частей: заборной 1 , калибрующей 2 и предохранительной 3 (рис. 4). Благодаря наличию заборного участка с углом конуса $\delta$ производится поверхностное упрочнение обрабатываемых зубьев. Формообразующей является поверхность калибрующего участка. В отличие от обкатника ИСМ, формообразующая поверхность является фасонной поверхностью вращения с радиусом $R_{\kappa p}$, геометрически не отличаю- 
щаяся от поверхности бочкообразного зуба, сопрягаемого со сферическим цилиндрическим зубчатым колесом. Плоскость симметрии калибрующего участка, отстоящая от торца на расстоянии $b$, должна во время обработки совпадать с касательной к линии нормальных шагов сферического колеса. Значения параметров $b, \quad c$ и $\delta$ определяют условия поверхностного деформирования. Процесс калибрования обкатниками (в том числе и твердосплавными) может повысить на одну степень точность зубчатых колес и уменьшить шероховатость обрабатываемой поверхности.

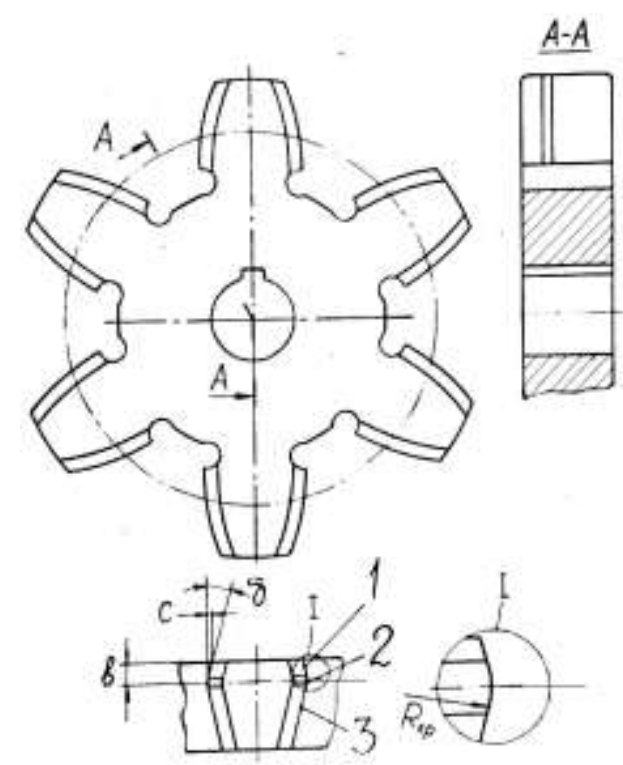

Рис. 3. Рабочий чертеж алмазного эластичного хона для окончательной обработки сферического зубчатого колеса с постоянным нормальным шагом

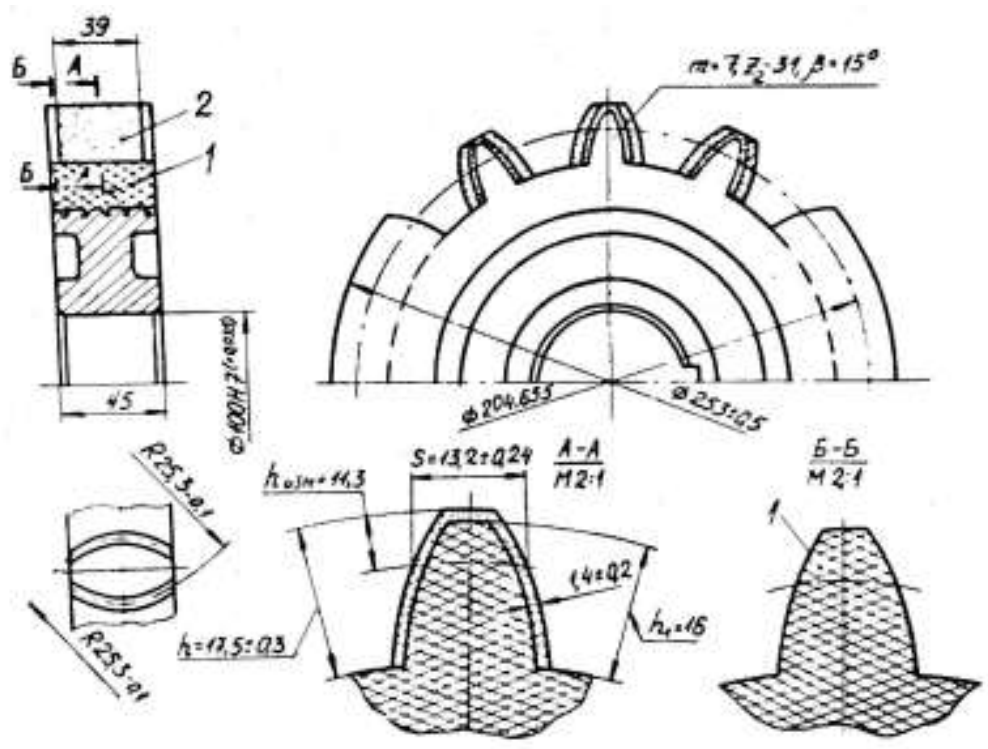

Рис. 4. Инструмент для калибрования сферических зубчатых колес 
Если каждый зуб описанного инструмента снабдить с торца со стороны заборной части передней поверхностью, можно получить режуще-деформирующий обкатник и тем самым добиться увеличения производительности за счет совмещения операций. Кроме того, при определенном соотношении между длиной заборного участка и величиной пропуска под поверхностное деформирование повышается точность формообразования и долговечность обработанных колес.

Общим свойством всех описанных инструментов является то, что они основаны на производящей поверхности, совпадающей $\mathrm{c}$ рабочей поверхностью цилиндрического колеса, сопрягаемого со сферическим [10-12]. Другими словами, здесь использован принцип совпадения станочного и рабочего зацеплений. Поэтому предлагаемые инструменты шевер, абразивный хон и обкатники могут быть рекомендованы для окончательной обработки.

На базе цилиндрического производящего колеса можно спроектировать многозубый лезвийный обкаточный инструмент для предварительного нарезания сферических зубчатых колес с постоянным нормальным шагом (рис. 5). Применительно к традиционным цилиндрическим колесам такой инструмент называют обкаточным резцом для зуботочения [13].

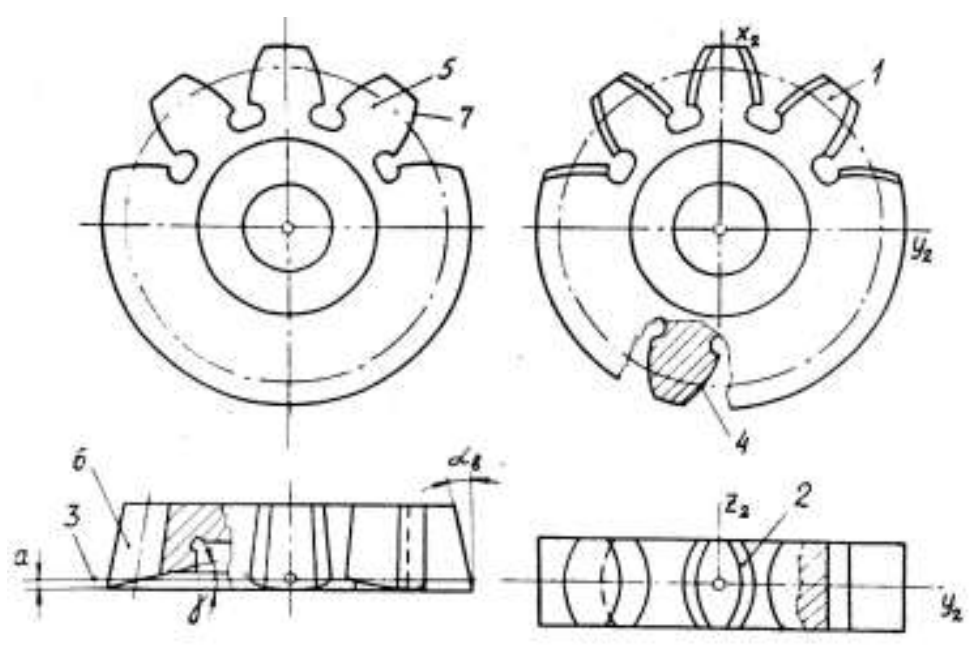

Рис. 5. Производящее цилиндрическое колесо и обкаточный лезвийный инструмент на его основе

Зоны наибольшей вероятности распределения точек контакта сопрягаемых поверхностей цилиндрического и сферического зубчатых колес находятся вблизи нормального сечения плоскостью 3, проходящей через межцентровую прямую. В связи с этим наиболее целесообразной представляется следующая методика профилирования указанного лезвийного обкаточного инструмента:

а) производящая

поверхность (например, поверхность вращения 2, ограничивающая бочкообразный зуб 1) считается заданной; в качестве основы для профилирования используется исходный профиль производящей поверхности 4 в нормальном сечении 3 (эвольвента, окружность или другая заданная кривая);

б) винтовым движением исходного профиля образуется винтовая боковая задняя поверхность зуба инструмента 6;

в) в пересечении задней поверхности с конической передней поверхностью 5 получается фасонная режущая кромка 7. 
Если исходный профиль с параметром $\varsigma$ задать уравнениями

$$
\begin{aligned}
& x_{0}=f_{1}(\varsigma) ; \\
& y_{0}=f_{2}(\varsigma) ; \\
& z_{0}=f_{3}(\varsigma),
\end{aligned}
$$

то уравнения винтовой задней поверхности с параметрами $\varsigma, \theta^{\prime}$ в системе координат инструмента будут иметь вид (рис. 6):

$$
\begin{aligned}
& x_{2}=f_{1}(\varsigma) \cos \theta^{\prime}-f_{2}(\varsigma) \sin \theta^{\prime} ; \\
& y_{2}=f_{1}(\varsigma) \sin \theta^{\prime}+f_{2}(\varsigma) \cos \theta^{\prime} ; \\
& z_{2}=f_{l}(\varsigma)+p \theta^{\prime},
\end{aligned}
$$

или

$$
\begin{aligned}
& x_{2}=x_{0} \cos \theta^{\prime}-y_{0} \sin \theta^{\prime} ; \\
& y_{2}=x_{0} \sin \theta^{\prime}+y_{0} \cos \theta^{\prime} ; \\
& z_{2}=z_{0}+p \theta^{\prime},
\end{aligned}
$$

где $\theta^{\prime}$ - текущий угол поворота исходного профиля;

$$
\begin{aligned}
& p \text { - параметр винта; } \\
& x_{0}, y_{0}, z_{0}-\text { координаты точек }
\end{aligned}
$$
исходного профиля.

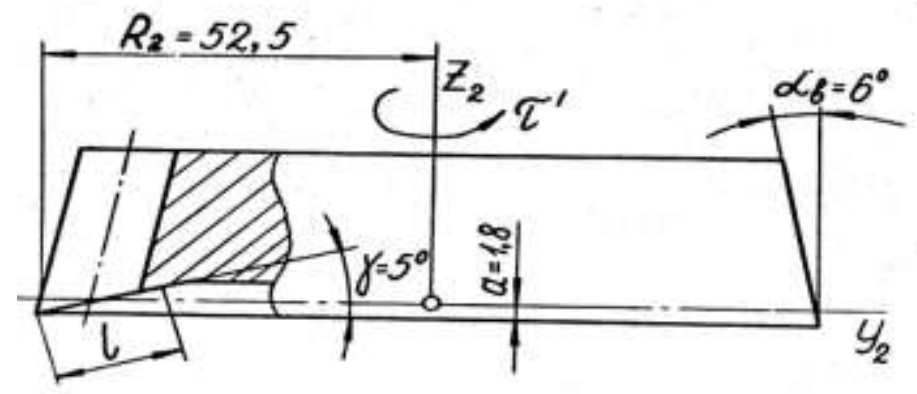

Рис. 6. Схема получения задней поверхности

Переднюю коническую поверхность с параметрами $\tau^{\prime}, l^{\prime}$ в той же системе координат можно получить вращением образующей (рис. 7):

$x_{2}=\left(R_{2}+\operatorname{atg} \alpha_{B}\right) \sin \tau^{\prime}-l^{\prime} \cos \gamma \sin \tau^{\prime} ;$

$y_{2}=-\left(R_{2}+\operatorname{atg} \alpha_{b}\right) \cos \tau^{\prime}+l^{\prime} \cos \gamma \cos \tau^{\prime}$;

$z_{2}=-a+l^{\prime} \sin \gamma$,

где $l^{\prime}$ - текущая длина образующей конуса;

$\tau^{\prime} \quad-$ текущий угол поворота образующей;

$a$ - расстояние от нормального сечения до торцовой плоскости, проходящей через наиболее удаленную от оси точку режущей кромки;

$$
\gamma \text { - передний угол. }
$$

Решая совместно уравнения (6) и (7), получаем связи между параметрами, которые будут удовлетворять точкам режущей кромки:

$$
\begin{aligned}
& \theta^{\prime}=\frac{\left(\sqrt{x_{0}^{2}+y_{0}^{2}}-R_{2}-\operatorname{atg} \alpha_{\theta}\right) \operatorname{tg} \gamma+z_{0}+A}{p} ; \\
& l^{\prime}=\frac{R_{2}+\operatorname{atg} \alpha_{b}-\sqrt{x_{0}^{2}+y_{0}^{2}}}{\cos \gamma} ; \\
& \tau^{\prime}=\arcsin \frac{x_{0} \cos \theta^{\prime}-y_{0} \sin \theta^{\prime}}{\sqrt{x_{0}^{2}+y_{0}^{2}}} .
\end{aligned}
$$



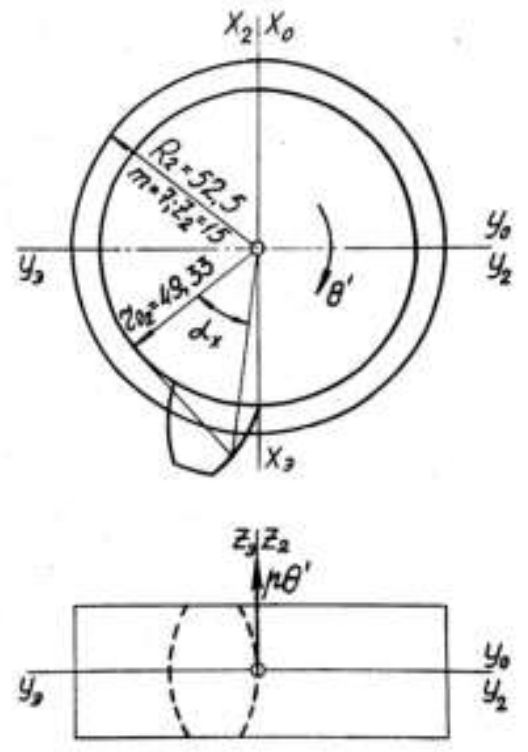

Рис. 7. К выводу уравнений передней поверхности точек фасонной режущей кромки в системе координат $x_{2} y_{2} z_{2}$

Профилирование может быть выполнено по следующему алгоритму:

- задавшись массивом значений параметра исходного профиля $\varsigma$, по уравнениям (4) получаем исходные координаты точек этого профиля $x_{0}, y_{0}, z_{0}$, каждой из которых соответствует конкретная винтовая линия задней поверхности;

- подставляя эти координаты и постоянные параметры $R_{2}, a, p, \alpha_{b}, \gamma \quad$ в формулу (8), подсчитываем значения угла $\theta^{\prime}$, соответствующие пересечению каждой из указанных винтовых линий с передней поверхностью;

- подставляя $\theta^{\prime} \quad$ и $\quad x_{0}, y_{0}, z_{0} \quad$ в уравнения (6), получаем искомые координаты.

Рассмотрим конкретный пример расчета. Пусть производящее цилиндрическое колесо с эвольвентным профилем имеет следующие исходные данные: модуль $m=7$ мм; число зубьев $z_{2}=15$; радиус делительной окружности $R_{2}=52,5$ мМ; радиус основной окружности $r_{0_{2}}=49,334$ мм; угол зацепления $\alpha=30^{\circ}$. Зададим передний угол $\gamma=5^{\circ}$; задний угол на вершине $\alpha_{в}=6^{\circ}$.

Исходным профилем в данном случае является эвольвента с параметром $\alpha_{x}$, и уравнения (4) в системе координат $x_{\ni} y_{\ni} z_{\text {э }}$ имеют следующий конкретный вид:

$$
\begin{aligned}
& x_{\ni}=\frac{r_{0_{2}}}{\cos \alpha_{x}} \cos \left(\operatorname{tg} \alpha_{x}-\alpha_{x}\right) ; \\
& y_{\ni}=\frac{r_{0_{2}}}{\cos \alpha_{x}} \sin \left(\operatorname{tg} \alpha_{x}-\alpha_{x}\right) ; \\
& z_{\ni}=0 ;
\end{aligned}
$$

в системе $x_{0} y_{0} z_{0}$

$$
\begin{aligned}
& x_{0}=x_{2}=-\frac{r_{0_{2}}}{\cos \alpha_{x}} \cos \left(\operatorname{tg} \alpha_{x}-\alpha_{x}\right) ; \\
& y_{0}=y_{2}=-\frac{r_{0_{2}}}{\cos \alpha_{x}} \sin \left(\operatorname{tg} \alpha_{x}-\alpha_{x}\right) ; \\
& z_{0}=z_{2}=0 ;
\end{aligned}
$$


Расчет шага и параметра винта выполнен по известным рекомендациям [14]:

$$
\begin{aligned}
& P=\frac{2 \pi R_{2}}{\operatorname{tg} \alpha_{b} \operatorname{tg} \alpha}=8612,721 \mathrm{MM} \\
& p=\frac{P}{2 \pi}=1370,757 \mathrm{MM}
\end{aligned}
$$

Направление винтовой поверхности для разноименных боковых сторон профиля (правое или левое) учитывалось знаками угла $\theta^{\prime}$ и расстояния $a$. Положительными приняты значения $\theta^{\prime}$, соответствующие вращению против часовой стрелки, если смотреть с конца оси $z_{2}$. Значение величины параметра $a$ учитывается со знаком плюс, если режущая кромка расположена по $z_{2}$ ниже, чем исходный профиль. Исходные координаты профиля, подсчитанные по уравнениям (9), и результаты аналитического профилирования представлены в таблице и на рис. 8.

Анализ результатов расчета показал, что боковая сторона 2 режущей кромки смещена относительно соответствующей стороны 1 исходного профиля вокруг и вдоль оси инструмента. Знаки углового и линейного смещений соответствуют правому винту, заложенному в расчет, что подтверждает правильность используемых уравнений и методики профилирования.

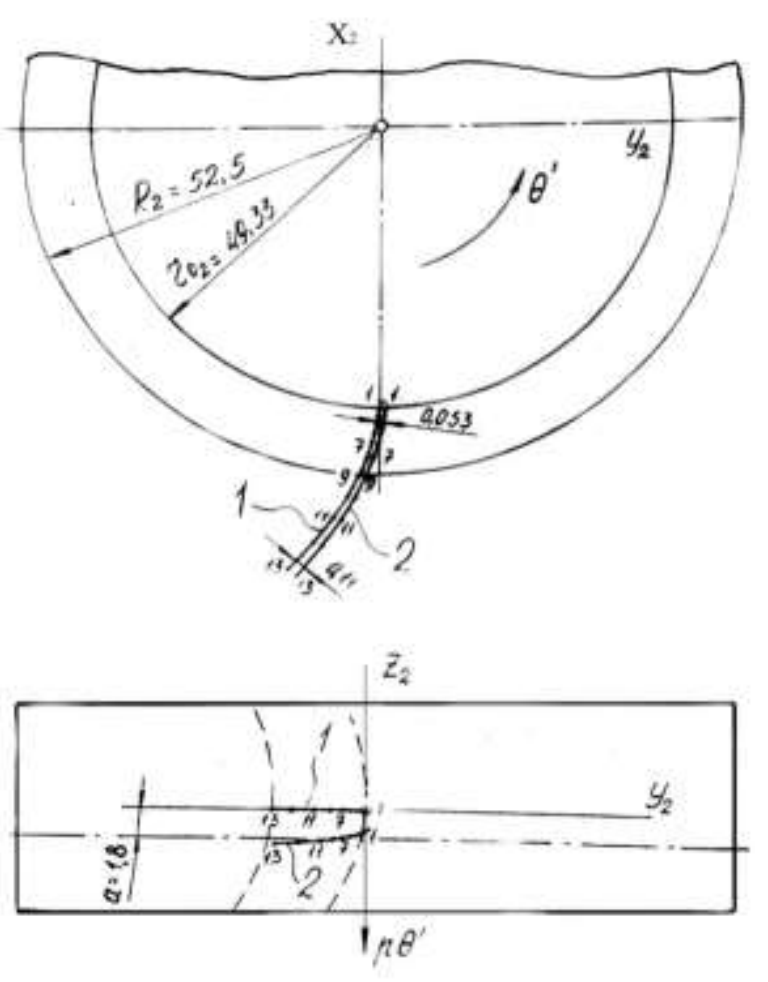

Рис. 8. Результаты профилирования конкретного инструмента

Профиль режущей кромки нового инструмента имеет большую ширину по сравнению с исходным профилем. Из-за большой величины шага винта по сравнению с расстоянием между исходным профилем и режущей кромкой текущий угол $\theta^{\prime}$ очень мал. Поэтому различия между исходным профилем и режущей кромкой незначительны: по высоте 0,0227 мм, по ширине от 0,106 мм на ножке зуба до 0,22 мм на головке (см. таблицу). По мере переточки инструмента эти 
различия будут уменьшаться, достигнув нуля в нормальном сечении, а при дальнейших переточках вновь возрастать с обратным знаком, так что при достижении $a=-1,8$ мм ширина профиля режущей кромки предельно переточенного инструмента будет меньше ширины исходного профиля [15].

Таблица

Результаты расчета координат точек фасонной режущей кромки

\begin{tabular}{|c|c|c|c|c|c|c|c|c|}
\hline \multirow[t]{2}{*}{$\begin{array}{l}\text { Номер } \\
\text { точки } \\
\text { профиля }\end{array}$} & \multirow{2}{*}{$\begin{array}{l}\text { Значение } \\
\text { параметра } \\
\text { эвольвенты } \\
\alpha_{x}, \text { град }\end{array}$} & \multicolumn{3}{|c|}{$\begin{array}{c}\text { Координаты точек } \\
\text { исходного профиля, } \\
\text { мм }\end{array}$} & \multirow{2}{*}{$\begin{array}{c}\text { Текущее } \\
\text { значение } \\
\theta^{\prime}, \text { рад }\end{array}$} & \multicolumn{3}{|c|}{$\begin{array}{c}\text { Координаты точек фасонной } \\
\text { режущей кромки, мм }\end{array}$} \\
\hline & & $\mathrm{x}_{0}$ & $\mathrm{y}_{0}$ & $\mathrm{z}_{0}$ & & $\mathrm{x}_{0}$ & $\mathrm{y}_{0}$ & $\mathrm{z}_{0}$ \\
\hline 1 & 0 & $-49,3342$ & 0 & 0 & $-0,001069$ & $-49,3339$ & $+0,0527$ & $-1,4654$ \\
\hline 2 & 3 & $-49,4020$ & $-0,0024$ & 0 & $-0,001073$ & $-49,4019$ & $+0,0506$ & $-1,4710$ \\
\hline 3 & 6 & $-49,6061$ & $-0,0190$ & 0 & $-0,001086$ & $-49,6059$ & $+0,0349$ & $-1,4895$ \\
\hline 4 & 9 & $-49,9492$ & $-0,0653$ & 0 & $-0,001108$ & $-49,9490$ & $-0,0096$ & $-1,5198$ \\
\hline 5 & 12 & $-50,4361$ & $-0,1571$ & 0 & $-0,001139$ & $-50,4361$ & $-0,096$ & $-1,5614$ \\
\hline 6 & 15 & $-51,0744$ & $-0,3114$ & 0 & $-0,001180$ & $-51,0743$ & $-0,2541$ & $-1,6177$ \\
\hline 7 & 18 & $-51,8701$ & $-0,5582$ & 0 & $-0,001231$ & $-51,8706$ & $-0,4943$ & $-1,6874$ \\
\hline 8 & 21 & $-52,9842$ & $-0,9160$ & 0 & $-0,001293$ & $-52,8371$ & $-0,8482$ & $-1,7727$ \\
\hline 9 & 24 & $-53,9843$ & $-1,4230$ & 0 & $-0,001367$ & $-53,9862$ & $-1,3498$ & $-1,8742$ \\
\hline 10 & 27 & $-55,3282$ & $-2,1191$ & 0 & $-0,001454$ & $-55,3310$ & $-2,0382$ & $-1,9930$ \\
\hline 11 & 30 & $-56,8841$ & $-3,0602$ & 0 & $-0,001556$ & $-56,8892$ & $-2,9715$ & $-2,1335$ \\
\hline 12 & 33 & $-58,6650$ & $-4,3174$ & 0 & $-0,0017$ & $-58,6720$ & $-4,2193$ & $-2,2454$ \\
\hline 13 & 36 & $-60,6871$ & $-5,9803$ & 0 & $-0,0018$ & $-60,6972$ & $-5,8702$ & $-2,4843$ \\
\hline
\end{tabular}

Таким образом, фасонная режущая кромка не лежит на поверхности бочкообразного зуба производящего колеса в течение почти всего срока службы инструмента и отличается от теоретического профиля зуба в нормальном сечении. Это сказывается на геометрической точности формообразования. Поэтому такие многозубые обкаточные лезвийные инструменты можно рекомендовать только для предварительной обработки сферических колес.
Выводы и перспективы дальнейшего развития в данном направлении. Применение описанных и рекомендуемых методов формообразования, конструкций режущих и деформирующих инструментов и методики их проектирования могут перевести вопросы использования двухпараметрических зубчатых колес с постоянным нормальным шагом в реальную плоскость.

Теоретические результаты работы обеспечивают полный набор информации, необходимой для практической реализации процессов формообразования зубчатых колёс с эквидистантными зубьями.

\section{Список литературы}

1. Ковалюх, В.Р. Двухпараметрические колёса с равновысокоширокими зубьями и впадинами [Текст] / В.Р. Ковалюх // Машиностроение. - 1982. - № 1. - С. 43-45. 
2. Коваюх, В.Р. Новый способ регулирования скорости вращения зубчатой передачи и синтез на его основе зубчатых вариаторов [Текст] / В.Р. Ковалюх, Р.В. Ковалюх // Теория механизмов и машин. - Харьков, 1988. - Вып. 44. - С. - 107-112.

3. Ковалюх, В.Р. Синтез зубчатых вариаторов на основе колёс с равновысокоширокими зубьями и впадинами [Текст]: дис.... канд. техн. наук / В.Р. Ковалюх. - Харьков, 1982. $156 \mathrm{c}$.

4. Кривошея, А.В. Особенности совместного геометрического проектирования зубчатых колёс и зубообрабатывающих инструментов [Текст] / А.В. Кривошея // Труды междунар. конф. «Высокие технологии в машиностроении: тенденции развития, менеджмент, маркетинг». - Харьков: ХГПУ, 1997. - С. 291.

5. Кривошея, А.В. Структура многопараметрического отображения, обобщающая станочные и рабочие зубчатые зацепления [Текст] / А.В. Кривошея // Труды междунар. конф. «Высокие технологии в машиностроении: моделирование, оптимизация, диагностика». - Харьков: ХГПУ, 1995. - С. 71.

6. Интегрированные технологии ускоренного прототипирования и изготовления [Текст] / под ред. д-ра техн. наук Л.Л. Товажнянского, д-ра тех. наук А.И. Грабченко. - Харьков: ОАО «Модель Вселенной», 2002. - 140 с. - Язык русский. ISBN 966-7875-12-1.

7. Тернюк, Н.Э. Проектирование инструментов для формообразования зубчатых колес двухпараметрических зацеплений с постоянным нормальным шагом [Текст] / Н.Э. Тернюк, Е.Б. Кондусова // Прогрессивные процессы механической обработки труднообрабатываемых материалов. - Мариуполь, 1989. - С. 58-59.

8. Гавриленко, В.А. Зубчатые передачи в машиностроении [Текст] / В.А. Гавриленко. - М.: Машгиз, 1962. - 252 с.

9. Тернюк, Н.Э. Абразивная обработка криволинейных зубьев сферических колес с постоянным нормальным шагом [Текст] / Н.Э.Тернюк, Н.А. Беззубенко, Е.Б. Кондусова // Интенсификация и автоматизированная разработка отделочно-зачистной и упрочняющей обработки. - Ростовн/Д: РИСХМ, 1989. - С. 101-102.

10. 3D-моделирование инструментов, формообразования и съема припуска при обработке резанием [Текст] / под ред. П.Р. Родина / А.И. Грабченко, Е.Б. Кондусова, А.В. Кривошея, Н.С. Равская, П.Р. Родин. - Харьков: НТУ «ХПИ», 2001. - 304 с.

11. Зубкова, Н.B. Методика 3D-моделирования режущих кромок и профилей режущих инструментов [Текст] / Н.В. Зубкова, Е.Б. Кондусова, О.Н. Кушнаренко // Высокие технологии: тенденции развития. - Харьков: НТУ «ХПИ», 2002. - Вып. 62. - С. 172-176.

12. Перепелица, Б.А. Приложение многопараметрических отображений к задачам 3Dмоделирования режущих инструментов и съема припуска [Текст] / Б.А. Перепелица, Е.Б. Кондусова // Резание и инструмент в технологических системах. - Харьков: НТУ «ХПИ», 2001. - Вып. 60. - С. 183-189.

13. Обкаточные резцы для зуботочения сферических зубчатых колес с постоянным нормальным шагом [Текст] / И.Е. Дюмин, Н.Э. Тернюк, Ю.В. Дудукалов [и др.] // Интерпартнер-92: тез. докл. - Харьков: ХПИ, 1992. - С. 86-88.

14. Родин, П.Р. Металлорежущие инструменты [Текст] / П.Р. Родин. - К.: Вища шк., 1979. $-431 \mathrm{c}$.

15. Кондусова, Е.Б. Анализ влияния характера задних поверхностей зуборезных долбяков на параметры обрабатываемых колес [Текст] / Е.Б. Кондусова // Высокие технологии: тенденции развития: тез. докл. междунар. конф. «Интерпартнер - 2005». Харьков: НТУ «ХПИ», 2005. - Вып. 72. - С 16-17. 
Ключевые слова: зубчатое зацепление, двухпараметрическое зубчатое колесо, обкаточные инструменты, шевер, зубчатый хон, режуще-деформирующие обкатники с точечным контактом.

\section{Аннотации}

Запропоновано ряд методів формоутворення та обкатних інструментів для попередньої й остаточної обробки зубчастих коліс 3 постійним нормальним кроком для спеціальних двопараметричних зачеплень. Виконано аналітичний опис кінематики процесу зубонарізання i геометрії обкатних інструментів, які засновані на виробничій поверхні. Доведено доцільність використання рекомендованих методів формоутворення та інструментів.

Предложен ряд методов формообразования и обкаточных инструментов для предварительной и окончательной обработки зубчатых колес с постоянным нормальным шагом для специальных двухпараметрических зацеплений. Выполнено аналитическое описание кинематики процесса зубонарезания и геометрии обкаточных инструментов, основанных на производящей поверхности. Доказана целесообразность использования рекомендованных методов формообразования и инструментов.

A number of forming methods and rolling action tools for the preliminary and final treatment of gear-wheels with the permanent normal step for the special two-parameter gearing have been proposed. The analytical description of gearcutting kinematics and rolling action tools geometry, based on the generating flat, has been performed. The expedience of recommended forming methods and rolling action tools has been substantiated. 